supra-renal bodies were crushed and left to be absorbed in situ no toxic symptoms resulted; therefore they did not contain the poison they might be supposed to excrete. 'The toxæmia produced by experimental removal of the suprarenal bodies had been shown to be counteracted by the injection of supra-renal extract. If these organs excreted poisons of the same nature as those accumulating on their removal and thus producing toxic symptoms, injection of the extract would only intensify the existing toxæmia. Again, Abelons and Langlois found that experimental removal of the organs gave rise to a toxic effect analogous to that of curare, while Schüfer and Oliver had shown that the physiological effect of the extract was not at all comparable to that of curare. Therefore the body or bodies giving rise to a toxic condition of the blood in "acapsulated" animals were not the same as the astive principles of supra-renal extract. There was therefore, strong evidence that the supra-renal bodies did not remove effete blood pigment or excrete and metabolise toxins, and that their function was not excretory.

Theory that adorson's Disease was Due to InadeQUate Secretion bY THE SUPRa-lienal Bodies.

This alternative view was strongly supported by the observations of Abelous and Langlois and Schüfer and Oliver. The latter observers had found that, while the healthy supra-renal bodies of man yielded an active extract, these organs in Addison's disease provided an extract which was absolutely inert. What was the method of action of this internal secretion? 1. It might possibly antagonise poisons resulting from the general metabolism of the body in two ways : (a) By exerting a ferment-like action on and thus destroying it. If its actire principle was a ferment, the activity of the extract would be destroyed by boiling. Moore had shown that, although long-continued boiling abolished the activity of the extract, boiling for some minutes did not have this effect. This view, therefore, was improbable. (b) By directly neutralising the toxic bodies in a manner annlogons to the action of an alkali on an acid. Schärer and Oliver's experiments showed that the extract had a definite physiological effect on healtby animals; hence the secretion did not act merely as a chemical antidote. To prove whether the extract had any action at all analogous to that of a chemical antidote experiments like that of Buchner with tetanus toxin and antitoxin should be made. 2. The secretion might act as a stimulus to the various tissues of the body. The researches of Schäfer and Oliver were in favour of this view. This tonic influence might act- $(a)$ by regulating their nutrition and activity and preventing the formation of any toxic bodies; or $(b)$ by increasing the resistance and defensive powers of the tissues, including the white blood-corpuscles, so that they were thus enabled to resist and to destroy the toxic bodies produced by the metabolism of the body. The later hypothesis was attractive, but as yet there was not sufficient evidence to warrant ary definite opinion.

In conclusion, Addison's disease was due to inadequate sapra-renal secretion, but whether the deficiency in this internal secretion allowed a toxic condition of the blood to develop, or whether it led to a general atony and apathy, could not be settled at the present stage of our knowledge.

Tre.itument.

The treatment of Addison's disease by supra-renal extract was yet in its infancy. Dr. G. Oliver had recorded two cases which had reacted in a satisfactory way, in that the pigmenta tion diminished, nausea disappeared, and weight was gained. The lectursr had had a case of Addison's disease under treatment since Jane, 1894 ; pigmentation remained, but nausea and languor had been relisved. It was important to ascertain the appropriate dose of the extract, otherwise its therapeutic value might be discredited from the employment of inadequate quantities. Forty-four grains of the gland in the day were not an excessive dose, though this was about the weight of the medullary parts (the active portions) of both human supra-renals. Artificial gastric digestion did not impair the activity of the extract, so the administration by the mouth was physiologically correct. ${ }^{2}$ Dr. G. Oliver had suggested the therapentic use of supra-renal extract as a bæmostatic in purpura, hæmophilia, \&c., and in exophtbalmic goitre, cyclic albuminuria, diabetes, and in the conditions of vaso-motorial paresis associated with the menopause.

2 Schuifer and Oliver: Procectings of the Physiological Society, March 16th, 1895

\section{AN OPERATION SUGGESTED FOR SOME CASES OF INTUSSUSCEPTION.}

BY F. T. PAUL, F.R.C.S. ENG., SURGEON TO TTIE TIVERPOAL ROYAL INTIRMARY.

WHEs the abdomen is opened for intestinal obstruction and an irreducible intussusception is discovered to be the source of the mischief some form of enterotomy or enterce. tomy is absolutely necessary. It is too often urged that some specific operation is the only right and proper means to adopt under the circumstances; but experience very soon teaches that there is no kind of intestinal obstruction for the relief of which there is only one best method. The parying circumstances of each case should be met by various procedures, and the surgeon shonld be prepared to meet the many unlooked-for difficulties which appear in almost every laparotomy undertaken for this condition. Cases of acute intussusception in cbildren are a little less fatal under medical treatment than those in which the obstruction is dne to other canses. For this reason the majority of them come under the surgeon's hands at a very late stage of the case, and it is unfortunately the rule rather than the exception to find them in a state of collapse and totally unfit for an extensive resection of bowel. In such cases it is simply throwing away the last chance of life to attempt anything more than the establishment of an artificial anus or a fæcal fistula. Again, there are other patients in whom the constitutional condition
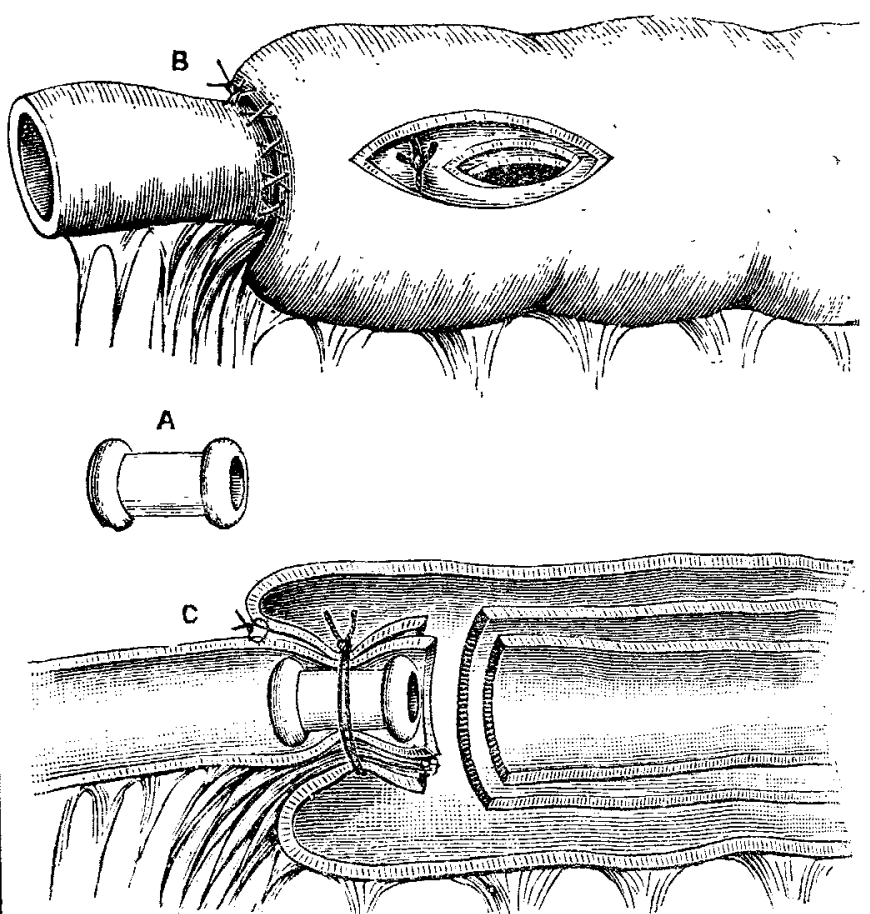

A, Light metal tube with expanded, rounded ends. B, Incisions in the bowel, and ligature in situ. c, Diagramatic
section of invaginated bowel, showing position of tube.

may be better whilst the intussusception itself is hopelessly irremediable from gangrene or some other cause. In such enterectomy is imperative, and one has to deciỏe atter removing the damaged bowel whether the patient will have the better chance by immediately approximating the ends of by bringing them ont of the abdomen and approximating liter. When collapse and gangrene are both present-and they are generally associated-few, I think, would hesitate in deciding upon the latter course; but when the patient is in fair condition these are suitable cases for immediate approximation, and it only remains to determine which method best fits the circumstances present. Fortunately, in many patients the condition is less grave, and in these an operation or the lines first suggested by Mr. A. E. Barker ${ }^{2}$ seems to be the best. The object of this short communice. tion is to propose a modification of his method which may possibly prove serviceable in some cases. When the invagination is short and easily brought out through the incision in the outermost or receiving layer of the intas. susception Mr. Barker's operation perhaps leaves nothing to be desired; but when the invagination is too extensive fot 
this, and has to be divided in situ, the operation certainly has dangers. There are many large vessels in the invaginated mesentery which, being at the bottom of the wound, are difficalt to get at, and cannot be readily controlled by sutures as in the slighter cases; also the tendency which the large stamp of mesentery has to retract when the weight is removed is so great that the preliminary sutures are liable to tear out, thus releasing the invagination and rendering it necessary to approximate the ends by another method or bring them ont of the abdomen. I therefore propose that the surgeon should be armed with a short metal tube made of aluminiam and shaped somewhat as in the engraving (Fig. A). The preliminary sutures-very few of which are requiredconnecting the intussusceptum with the intussuscipiens and the first incisions are made as recommended by Mr. Barker ; then the retarning and entering layers are also respectively incised (see Fig. B), and the tube grasped with forceps is pashed into the position shown in Fig. C. A stout silk ligature is now made to surround the intussusceptum just abore the incisions in it, and is tightly tied. Finally, the intassusceptam is cat off below the ligature and withdrawn, and the wound in the outer layer is closed in the usual way.

I have not yet had the opportanity of trying this plan, and as one may have to wait indefinitely for a suitable case I make the suggestion public, in order that if any other sargeon is so disposed he may give it a trial. The end aimed at is exactly the same as that attained by other methods ; but it seems to me that there are certain advantages, of which the following, if real, are important: (1) a saving of time, as the ligature replaces many sutures and also closes the bloodvessels before they are divided ; (2) the operation is practically bloodless ; and (3) disengagement of the invaginated stump is impossible, as it is firmly held by the ligature for at least three days.

Rodney-street, Liverpool.

\section{A CASE OF RABIES.}

BY B. KE M P, M.R.C.S. ENG., \&C., MEDICAL OFFICER OF HEALTH, HORBLRY.

$A B 0 \times$ ten years of age was bitten in the lower lip by a strange dog on Saturday, Nor. 17th, 1894. He at once told his father. The latter and some other men gave chase to the animal, but it got away, and has not been seen or beard of since. The father said it was a black-and-tan sheep dog. He thought it was rather lame and ran in a staggering manner, like a person half drunk. The boy was brought to my surgery about an hour after being bitten. The lower lip was torn quite through, leaving a small gaping wound. I washed and dressed it with boracic acid and inserted one suture, and ordered the wound to be dusted occasionally with boracic acid powder. I saw the patient again on the Monday and Thursday following the day of the accident; the wound was quite healed, and the boy appeared well. I may say that it was not known that the dog was rabid. The patient's motber told me that he went to school after staying at home for a week, and did so until Dec. 8th. Daring this time he had not eaten so well as usual, and bad become thinner, otherwise he appeared to be well. On Dec. 9th he first complained of not being able to swallow food or liquids so well as usual, and of thirst. On Dec. 10th he could not swallow anything, the thirst was worse, and he was now thought to be suffering from cold. He was ordered to have warm applications applied to the throat and to be kept warm in the house. He said his throat was not sore, but felt as if there was something lower down which prevented him from swallowing anything. He slept fairly well in the night. On Dec. 11th the symptoms were the same; a dose of castor-oil was given him by his mother; he swallowed a portion of it with great difficulty and was put to bed at 7 P.M. The boy did not sleep and awakened his mother about $3 \mathrm{~A} . \mathrm{M}$. on Dec. 12th by calling out. He was now very restless, looked wild, said he was going to die, and was unable to swallow anything. Soon after 6 A.M. he had the first real spasm, which alarmed his parents; he tried to jump out of bed whilst in it. His father came for me, and on hearing his account I suspected the nature of the illness and went at once. On arriving about $7 \mathrm{~A}, \mathrm{M}_{\mathrm{I}}$. Ifound the boy in great distress, with wild staring eyes, foaming at the mouth, constantly spitting, and the muscles of the neck rigid. I gave him a teaspoonful of a strong solution of chloral hydrate, most of which he got down, and it at once brought on spasm of the muscle of the pharynx and larynx, also of the thoracic muscles ; the eyes were almost protruding; there were lividity of the face and difficulty of breathing. Two men had the greatest difficulty to prevent him from springing out of bed. He complained of a strange sensation in the right arm; the fingers of the right hand were rigid, and he wanted some one to hold the hand. He was quite sensible and talkative, said he was going to die, and soon afterwards expressed a wish to see his clergyman, who came. On seeing the serious nature of the case I recommended the patient's immediate removal to the hospital at Wakefield, sent for a cab, and along with his father took him there. Soon after my arrival, and before removing him, he became much calmer and had no more convulsions until after his arrival at the hospital. On the way to the hospital the muscles of the neck were rigid and viscid, and frothy mucus was constantly working out of the month. He talked all the way sensibly, but seemed now afraid of our doing anything for him, such as covering him up in the blankets, and would do it for himself. He continued in this state until after arriving at the hospital, a journey of three miles, when he was at once put to bed. The convulsions now came on rapidly. The surgeon (Mr. Walker) and the house surgeons quite agreed with me as to the nature of the case. A strong hypodermic injection of morphia and strychnia was given, also chloral by the rectum. This kept him quiet for about an hour, and he slept. This I was told by the house surgeon. After an hour the spasms came on more frequently, and he died in one about 4 P.M. the same day, nothing appearing to have any effect upon them. He was conscious to the last.

IIorbury, Wakefield.

\section{DEGREES OF KNEE-JERK.}

\section{BY LEONARD J. KIDD, M.D. BRUX.}

For the last two years or more $I$ have been in the habit of recording the degrees of the knee-jerks by means of a scheme which was suggested to me in the following way:-I had often seen physicians mark a particular jerk as + or ++ with the purpose of conveying the meaning of exaggerated and greatly exaggerated respectively. These signs brought to my remembrance the well-known "Degrees of Intra-ocular Tension" of the late Sir W. Bowman. I thought one might frame a scheme of variuus degrees of knee-jerk by means of plus and minus symbols. It was clear to me that to be of any value, apart from that of saving time in clinical work, these signs must convey a definite meaning, so that any particular plus or minus jerk could be at once put in to a certain category. I found that there were three distinct groups of excess of jerks and three of diminution, the last being the itbsent jerk if I may speak of a diminished jerk as being an absent jerk. These, together with the normal degree, make up seven degrees; for those who wish to follow literally the analogy of Bowman's notification an additional plus query and minus query can be added, but I think these are not needed.

After very many attempts the best classification I can suggest is as follows:-

K.J.n. = normal jerk-i.e., of normal quickness and of normal excursion of the leg and foot. Right jerk written as R.K.J.n.; left jerk as L.K.J.n.

K.J. $+1=$ distinctly increased quickness and excursion, but not obtained by a blow above the patella. K.J. $+2=$ still more lively and extensive, and obtained by supra-patellar blow. K.J. $+3=$ as in $K J .+2$ but with addition of clonus of anterior thigh muscles; this is usually found, I think, only in cases where foot-clonus is also obtained.

K.J. -1 distinctly diminished quickness and excursion, but obtained wilhout reinforcement-e.g., by Jendrassik's method. K.J. $-2=$ still more sluggish, and obtained only with reinforcement. K.J. -3 or $0=$ absent even on reinforcement and after many careful trials by all known methods.

I occasionally find that both jerks come within the same category, bat one is more marked than in the other This have seen mostly in that very common class styled $\mathrm{K} \mathrm{J} .+2$. In such cases, if one jerk is about half way, as to quickness and excursion, between +2 and +3 , but the other very nearly as quick as +3 usually is, I call one $+2 \frac{1}{2}$ and the other +23 . By this means a still more accurate result is obtained than by simply calling both +2 . The same can be 